\title{
Phytochemical profiling of underexploited Fabaceae species: Insights on the ontogenic and phylogenetic effects over isoflavone levels
}

\author{
João C.M. Barreira a,b,*, Tatiana Visnevschi-Necrasov ${ }^{\text {b,c }}$, Graça Pereira ${ }^{\mathrm{d}}$, \\ Eugénia Nunes ${ }^{a}$, M. Beatriz P.P. Oliveira ${ }^{\mathrm{b}}$ \\ a REQUIMTE, Departamento de Ciências Químicas, Faculdade de Farmácia, Universidade do Porto, Rua Jorge Viterbo Ferreira, no 228, 4050-313, Portugal \\ b CIMO-ESA, Instituto Politécnico de Bragança, Campus de Santa Apolónia, Apartado 1172, 5301-855 Bragança, Portugal \\ c CIBIO-ICETA, Faculdade de Ciências, Universidade do Porto, R. Padre Armando Quintas, 4485-661 Vairão, Portugal \\ ${ }^{\mathrm{d}}$ INRB/IP - INIA - Instituto Nacional de Recursos Biológicos, Caia E São Pedro Estrada Gil Vaz, 7350-228 Elvas, Portugal
}

\section{A R T I C L E I N F O}

\section{Article history:}

Received 27 January 2016

Received in revised form 1 July 2016

Accepted 18 July 2016

Available online 20 July 2016

\section{Keywords:}

Isoflavones profile

Ontogenesis

Biserrula

Lotus

Ornithopus

Scorpiurus

LDA

\begin{abstract}
A B S T R A C T
There is an increasing trend towards finding alternative sources of valued phytochemicals due to their diverse potentialities in food industry and pharmaceutical applications. Phenolic compounds, in particular, have been the focus of several profiling reports, but isoflavones characterization has been studied in fewer cases and in a very limited group of plant species. Despite their acknowledged bioactivity, there's actually a strict number of plants validated for their isoflavones contents. In a previous report, we have identified nine Leguminosae species (from genera Biserrula, Lotus, Ornithopus and Scorpiurus) as potential alternative sources of these phenolic compounds. However, the isoflavone profiles are highly modulated by the ontogenic stage. Therefore, the present study was conducted in the same Leguminosae species, but harvested at three sequential vegetative development stages: vegetative elongation, late bud and late flowering, with the main purpose of assessing the evolution of isoflavones content throughout the plant development. In general, the plant species from Biserrula and Lotus genera showed the highest potential as new natural sources of isoflavones, especially owing their high levels of biochanin A. Independently of the plant species, it was possible to identify the phenologic stages where each of the quantified isoflavones is maximized. These findings are useful to predict isoflavone yields according to harvesting time, validating the potential use of the studied plants in innovative food formulations.
\end{abstract}

(c) 2016 Elsevier Ltd. All rights reserved.

\section{Introduction}

Fabaceae (or Leguminosae) is the third largest flowering plant family (surpassed only by Orchidaceae and Asteraceae), comprising 19,325 species organized in 727 genera. From an economical point of view, Fabaceae is actually the second most important plant family, being mainly used as a source of food and phytochemical compounds (Boerma, John, \& Molen, 2001). Curiously, fewer than 50 species provide $90 \%$ of the typical requirements, such as supplying human food, edible oils, animal fodder and forage, nitrogen fixation or providing a diversity of phytochemicals (Lewis, Schrire, Mackinder, \& Lock, 2005). This situation creates a serious need for alternative Fabaceae species with the potential to be used for similar purposes. In the case of isoflavone production, the studied species are usually limited to soybean

\footnotetext{
* Corresponding author at: REQUIMTE, Departamento de Ciências Químicas, Faculdade de Farmácia, Universidade do Porto, Rua Jorge Viterbo Ferreira, no 228, 4050-313, Portugal.

E-mail address: jbarreira@ipb.pt (J.C.M. Barreira).
}

(Glycine max L.) and red clover (Trifolium pratense L.). Nevertheless, some alternative species are being studied to evaluate their potential use as isoflavone sources (Barreira et al., 2015; Jacobs, Wegewitz, Sommerfeld, Grossklaus, \& Lampen, 2009; Spínola, Llorent-Martínez, Gouveia-Figueira, \& Castilho, 2016; Visnevschi-Necrasov et al., 2014, 2015). The species studied in this work (Biserrula pelecinus L., Lotus conimbricensis Brot., Lotus subbiflorus Lag., Ornithopus compressus L., Ornithopus pinnatus (Mill.) Druce, Ornithopus sativus Brot., Scorpiurus muricatus L., Scorpiurus vermiculata L. and Scorpiurus vermiculatus L.) are good examples of alternative sources of isoflavones (VisnevschiNecrasov et al., 2015). In general, these species are self-regenerating annual pasture legumes, nutritious and palatable, having deep radical system, good quality of hay and silage, compatibility with summergrowing perennial grasses and tolerance to high levels of soil aluminum (Hackney, Dear, \& Crocker, 2007). In some cases, they are inclusively tolerant to acid, sandy and duplex soils, allowing their cultivation in highly deprived regions (Nandasena et al., 2004). In addition, they have high resistance against insects and might control weeds that are not destroyed by herbicides, having also important actions (especially 
the species belonging to Lotus genus) in bacteria-plant symbiosis, mycorrhizal interactions and nitrogen metabolism (Diaz, Borsani, \& Monza, 2005).

From a phytochemical point of view, these species produce healthpromoting secondary metabolites that can exert important effects on human health (e.g., blood cholesterol-reduction, hypoglycemic action, prevention of certain types of cancer, and protective effects against atherogenesis, angiogenesis, nervous system diseases, menopausal symptoms and osteoporosis) (Gepts et al., 2005; Mortensen et al., 2009; Sacks et al., 2006). Isoflavones, due to their structural resemblance with estradiol, have been recognized for their ability to decrease the morbidity rates linked to age-related cardiovascular diseases and osteoporosis, breast and prostate cancers, and menopausal symptoms (Cano, García-Pérez, \& Tarín, 2010; Mourouti \& Panagiotakos, 2013; Park \& Weaver, 2012). These properties might render important pharmaceutical applications to these plant species, but their phytochemical profiles must be accurately characterize before being included in any novel product (Food Safety Commission Novel Foods Expert Committee, 2006; U.S. Department of Agriculture, 2008), particularly when those natural compounds are indicated as exerting some deleterious effects, such as the previously reported genotoxicity of isoflavones (Azarova et al., 2010; Setchell \& Cassidy, 1999; Ye et al., 2001).

Besides the genotypic factors, the ontogenic stage is an important modulator of isoflavones profile (Barreira et al., 2015; Bednarek et al., 2001; D'Agostina, Boschin, Resta, Anniccniarico, \& Arnoldi, 2008; Tsao, Papadopoulos, Yang, Young, \& McRae, 2006). To avoid biased effects induced by environmental factors, all plants were harvested in an experimental field. Isoflavones were extracted from the leaves of the nine selected species by matrix solid-phase dispersion (MSPD), and studied for the first time throughout different ontogenic stages: i) vegetative elongation, ii) late bud and iii) late flowering, allowing understanding profile changes along the plants' growth.

\section{Materials and methods}

\subsection{Standards and reagents}

Purity-corrected individual isoflavone stock solutions ( $1 \mathrm{~g} / \mathrm{L}$ ) were prepared in methanol: $\mathrm{H}_{2} \mathrm{O}(75: 25, \mathrm{v} / \mathrm{v})$. A composite stock standard solution of multiple isoflavones was prepared in methanol containing $40 \mathrm{mg} / \mathrm{L}$ of each standard: biochanin A $(\geq 97 \%)$, puerarin $(\geq 99 \%)$, glycitein ( $\geq 97 \%$ ), daidzein ( $\geq 98 \%$ ), daidzin ( $\geq 95 \%$ ), prunetin $(\geq 98 \%)$, genistein ( $\geq 98 \%$ ), genistin ( $\geq 95 \%)$ and formononetin ( $\geq 99 \%)$ were obtained from Sigma-Aldrich (St. Louis, MO, USA); pratensein, pseudobaptigenin and irilone (all $\geq 98 \%$ ) were from Chromadex Inc. (Barcelona, Spain). The internal standard (IS) 2-methoxyflavone was obtained from Sigma. A working IS solution was prepared in methanol at $1 \mathrm{~g} / \mathrm{L}$. All the solutions were stored at $-20^{\circ} \mathrm{C}$ in amber glass vials when not in use.

Methanol (HPLC grade) and formic acid (analytical grade) were from Merck (Darmstadt, Germany). Purified demineralized water was from a "Seradest LFM 20" system (Seral, Ransbach-Baumbach, Germany). The eluents were filtered through $0.45 \mu \mathrm{m}$ filters and degassed under reduced pressure and ultrasonic bath. Disposable syringe filter PTFE $0.45 \mu \mathrm{m}$ was from Macherey-Nagel (Düren, Germany). The $C_{18}$-bonded silica (particle size 55-105 $\mu \mathrm{m}$ ) used as sorbent for MSPD was from Waters (Milford, MA, USA). The limits of quantification and detection as well as the recovery of the method were acceptable as described previously (Visnevschi-Necrasov et al., 2015).

\subsection{Plant material and field experimental site}

Nine species of four Fabaceae genera (Biserrula, Lotus, Ornithopus and Scorpiurus) were cultivated from February to June of 2010, in the experimental field of the University of Porto at the Agrarian Station of Vairão, in Portugal. No chemical fertilizers were used and plants were not inoculated with nitrogen-fixing bacteria. Samples were collected in three phenologic stages: 1 - vegetative elongation (stem length $<30 \mathrm{~cm}$, no visible buds or flowers); 2 - late bud (three or more nodes with visible buds, no flowers or seed pods); and 3 - late flowering (one or more nodes with 50\% open flowers, no seed pods). The vegetal germplasm was obtained from the Portuguese collection of Leguminosae provided by the National Institute of Biological Resources (Instituto Nacional dos Recursos Biológicos, I.P.). Voucher specimens of each species were numbered and deposited in the local herbarium.

For each species, three independent samples were selected (in different locations within the limits of the indicated Experimental Field) consisting of fresh leaves from randomly selected plants ( 5 plants for each accession) belonging to 2 different accessions; samples were dried at $65^{\circ} \mathrm{C}$ for $72 \mathrm{~h}$ and milled, at particle size of $0.1 \mathrm{~mm}$, using an A11 analysis mill (IKA Werke, Staufen, Germany). Samples were stored in silicone tubes at room temperature.

\subsection{Extraction procedure}

MSPD extraction of isoflavones was applied with small modifications of a previous method (Visnevschi-Necrasov et al., 2015). An aliquot of $500 \mathrm{mg}$ of the previously milled dried sample, $2 \mathrm{~g}$ of $\mathrm{C}_{18}$ and $40 \mathrm{mg} / \mathrm{kg}$ of 2-methoxyflavone $(200 \mu \mathrm{L}$ at $100 \mathrm{mg} / \mathrm{L})$, used as internal standard, were placed in a glass mortar and blended with glass pestle for 2-3 min. This mixture was then transferred to an empty column connected to a vacuum system. The column was washed with $10 \mathrm{~mL}$ of distilled water (reddish-brown phase eluted from the column) and the isoflavones were eluted with $5 \mathrm{~mL}$ of methanol: $\mathrm{H}_{2} \mathrm{O}(9: 1, \mathrm{v} / \mathrm{v})$. Before HPLC analysis, the extracts collected in amber vials were filtered through a $0.45 \mu \mathrm{m}$ PTFE membrane. Different samples of two distinct accessions of all species were extracted.

\subsection{HPLC determination of isoflavones}

Chromatographic analyses were performed with a Jasco (Tokyo, Japan) high-performance liquid chromatograph equipped with a PU2080 quaternary pump and a Jasco AS-950 automatic sampler with a $20 \mu \mathrm{L}$ loop. Detection was performed with a Jasco model MD-2010 multi-wavelength diode-array detector (DAD). Chromatographic separation of the compounds was achieved with a Luna $5 \mathrm{U} \mathrm{C}_{18}$ column ( $5 \mu \mathrm{m}, 150 \times 4.60 \mathrm{~mm}$; Teknokroma, Barcelona, Spain) operating at $40{ }^{\circ} \mathrm{C}$. The eluent was a gradient of acetonitrile (A) and $0.1 \%$ formic acid (B), at a flow rate of $1 \mathrm{~mL} / \mathrm{min}$, with a linear gradient as follows: $0 \min 33 \%$ B, 7 min 45\% B, $15 \min 50 \%$ B, $25 \min 60 \%$ B, $30 \min 70 \%$, $35 \mathrm{~min} 50 \%$ B, 37 min 33\% B, maintaining these conditions for $10 \mathrm{~min}$ and returning to the initial ones after 3 min. Data were analyzed using the Borwin-PDA Controller Software (JMBS, Le Fontanil, France). Compounds were identified by chromatographic comparisons with authentic standards and UV spectra. Quantification was made by DAD at $254 \mathrm{~nm}$ based on the internal standard (2-methoxyflavone) method.

\subsection{Statistical analysis}

Two accessions of each species and phenologic stage were used. From each accession, three independent extractions were performed, and each of the extracts was injected twice, resulting in 36 values/species ( 2 accessions $\times 3$ stages $\times 3$ extractions $\times 2$ injections). Data were expressed as means \pm standard deviations. All statistical tests were performed at a 5\% significance level using the SPSS software, version 22.0 (IBM Corp., Armonk, NY, USA).

Initially, the effects of "plant species" (PSp) and "phenologic stage" $(\mathrm{PhS})$ in isoflavone profiles were evaluated through an analysis of variance (ANOVA) with type III sums of squares, performed using the Repeated Measures Analysis procedure of the General Linear Model. Since the independence of variables could not be assumed, there was a need to verify the sphericity criterion, which evaluates if the 
correlation between treatments is the same, assuming that variances in the differences among conditions are the same. Sphericity was evaluated trough the Mauchly's test; every time the sphericity assumption was violated, the Greenhouse-Geisser correction was applied. A 2-factor $\times 3$ levels matrix was studied.

In addition, a linear discriminant analysis (LDA) was used to evaluate the association of the genus and the PhS with the isoflavone profiles. A stepwise technique, using the Wilks' $\lambda$ method with the usual probabilities of $F$ (3.84 to enter and 2.71 to remove), was applied for variable selection. This procedure uses a combination of forward selection and backward elimination procedures, where before selecting a new variable to be included, it is verified whether all variables previously selected remain significant (Palacios-Morillo, Alcázar, Pablos, \& Jurado, 2013). With this approach, it is also possible to identify the significant variables that contribute in higher extent to the discrimination of a determined genus, in the first case, or a specific PhS, in the second case. To verify which canonical discriminant functions were significant, the Wilks' $\lambda$ test was applied. A leaving-one-out cross-validation procedure was carried out to assess the model performance.

\section{Results and discussion}

Besides being unequally distributed in the plant tissues and modulated by biotic and abiotic stress factors, isoflavone content depends on the ontogenic stage of a specific plant. However, and exempting some selected plant sources, such as soybean G. $\max , T$. pratense or Lupinus albus L. (D'Agostina et al., 2008; Tsao et al., 2006), the research on the isoflavones evolution during plant development is rather scarce (Bucar, 2013). Accordingly, this work was designed with the main purpose of evaluating the isoflavone fluctuations in response to ontogenic factors using nine different Fabaceae species. The current research in this area is usually focused on post-harvesting technologies to increase the yields in isoflavones. However, using upstream approaches, such as selecting the harvesting time that optimizes the production of a determined isoflavone, does not require the same level of technical skills as the downstream processes, which might convey important economic benefits.

\subsection{Isoflavone profiles}

Considering all the assayed plant species, eleven isoflavones were quantified (indicated by the elution order): puerarin (7,4'-dihydroxy-8$C$-glucosylisoflavone), daidzin (daidzein-7-O-glucoside), genistin (genistein-7-0-glucoside), daidzein (4',7-dihydroxyisoflavone), glycitein $\left(4^{\prime}, 7-\right.$ dihydroxy-6-methoxyisoflavone), genistein (4',5,7-trihydroxyisoflavone), pratensein (4'-methoxy-3',5,7-trihydroxyisoflavone), formononetin (7-hydroxy-4'-methoxyisoflavone), irilone (9-hydroxy-7-(4hydroxyphenyl)-[1,3]dioxolo[4,5-g]chromen-8-one), prunetin (4',5-dihydroxy-7-methoxyisoflavone) and biochanin A (5,7-dihydroxy-4'-methoxyisoflavone).

The experimental design was defined to evaluate the contribution of two different factors to modulate isoflavone profiles: i) the plant species (which is obviously related to their phylogeny) and ii) the phenologic stage (associated to their ontogenesis factors). To acquire unbiased results, it was mandatory to evaluate the effects of the plant species (PSp), independently of the phenologic stage (PhS) in which the plants were harvested, as well as the true effect of the latter, irrespectively of the PSp.

Hence, results were compared by a 2-way ANOVA following the generalized linear model coupled to the repeated measures analysis technique. In this analysis, it is important to check for the homogeneity of variances in the measures done for each assayed condition. Since the independence of variables cannot be assumed, the former requirement was evaluated by the Mauchly's sphericity test ( 1 is the highest value, while 0 is the lowest). Repeated measured analysis was chosen due to its higher sensitivity, either considering the reduction in the unsystematic variation, as well as its higher susceptibility to experimental effects.

Table 1 shows the isoflavone profiles as the mean value of each PSp considering the three $\mathrm{PhS}$, as well as mean value of each $\mathrm{PhS}$ including all PSp. The evaluated factors (PSp and PhS) showed a significant interaction $(\mathrm{PSp} \times \mathrm{PhS})$ in all cases, hampering the identification of specific effects for each individual factor through multiple comparison tests. Nevertheless, some overall trends were observed in the estimated marginal means plots (data not shown): Biserrula (B. pelecinus: $2739 \mathrm{mg} / \mathrm{kg} \mathrm{dm}$ ) and Lotus (L. conimbricensis: $3422 \mathrm{mg} / \mathrm{kg} \mathrm{dm}$; L. subbiflorus: $1308 \mathrm{mg} / \mathrm{kg} \mathrm{dm}$ ) genera were clearly the ones with the highest isoflavone content, especially owing to the contribution of bioachanin A. In fact, regarding this particular isoflavone, L. conimbricensis stood out as having higher quantities than those showed by red clover, which is the most acknowledged source of biochanin A (Krenn, Unterrieder, \& Ruprechter, 2002; Sivesind \& Seguin, 2005; Tsao et al., 2006). On the other edge, S. muricatus (106 mg/kg dm) and 0 . subbiflorus $(161 \mathrm{mg} / \mathrm{kg} \mathrm{dm})$ showed the lowest quantities in isoflavones.

Besides these quantitative differences, the isoflavone profiles obtained for each Fabaceae species revealed highly pronounced qualitative variance. In fact, genistin, dadzein, pratensein and irilone were the only isoflavones detected in all species, while puerarin was nearly absent in all cases, except for $S$. muricatus $(9.1 \mathrm{mg} / \mathrm{kg} \mathrm{dm})$ and $S$. vermiculatus $(2.0 \mathrm{mg} / \mathrm{kg} \mathrm{dm})$, which represent a strong evidence of the marked influence exerted by phylogenetic factors over the isoflavone profiles. 0 . compressus gave the highest contents in daidzin (99 mg/kg dm), while genistin (291 mg/kg dm) and daidzein (29 mg/ $\mathrm{kg} \mathrm{dm}$ ) showed maximal values in 0 . pinnatus. Scorpiurus genus, on the other hand, gave the maximal contents in glycitein $(51 \mathrm{mg} / \mathrm{kg} \mathrm{dm}$ in S. vermiculata), formononetin ( $88 \mathrm{mg} / \mathrm{kg} \mathrm{dm}$ in S. vermiculatus) and irilone (99 $\mathrm{mg} / \mathrm{kg} \mathrm{dm}$ in S. vermiculatus). Finally, Lotus genus proved its higher potential as a natural source of genistein, pratensein, prunetin (128, 265 and $63 \mathrm{mg} / \mathrm{kg} \mathrm{dm}$, respectively, in L. subbiflorus) and biochanin A (3186 mg/kg dm in L. conimbricensis). In fact, the high contents of biochanin A detected in both Lotus species and B. pelecinus represent a promising result considering that this $O$-methylated isoflavone is acknowledged for its neuroprotective (Wang et al., 2015), cardioprotective, nephroprotective (Jalaludeen et al., 2015), antitumoral (Piegholdt et al., 2014), antiviral and anti-inflammatory (Sithisarn, Michaelis, Schubert-Zsilavecz, \& Cinatl, 2013) activities. Furthermore, biochanin A might suffer demethylation by human hepatic enzymes, yielding genistein, which is also acknowledged for its biological activity (Tolleson, Doerge, Churchwell, Marques, \& Roberts, 2002). In Biserrula and Lotus genera, the genistein levels were similar to those reported in widely acknowledged species, e.g., soybean, in which genistein was reported as the major isoflavone ( 84 to $583 \mathrm{mg} / \mathrm{kg} \mathrm{dm}$ ), depending on the reproductive stages (Kumar, Rani, Dixit, Bhatnagar, \& Chauhan, 2009). The high relevance of this isoflavone is clearly demonstrated by the increasing number of registered patents, either describing the possible extraction processes or different food and pharmaceutical applications (Nemitz et al., 2016), as well as by different reports on its health effects (with emphasis on the anti-tumoral activity) (Russo et al., 2016).

Concerning ontogenic effects, changes in isoflavone profiles were lower in magnitude, despite being significant in all cases (Table 1). In general, plants in late bud (LB) stage tended to present higher isoflavone levels, which is in agreement with our previous results obtained with plant species from the Medicago genus (Barreira et al., 2015). Interestingly, among the 11 detected isoflavones, daidzin, genistin, pratensein, formononetin, irilone and biochanin $\mathrm{A}$ (where the most abundant are included), were maximized in this particular stage. Even so, puerarin, daidzein, genistein and prunetin, were detected in higher amounts in the vegetative elongation (VE) stage, while glycitein was maximized during late flowering (LF). These observations represent additional evidences of the strong interaction verified among PSp and PhS, as no unequivocal trend could be identified (Fig. 1). 
Table 1

Isoflavone contents ( $\mathrm{mg} / \mathrm{kg}$ of dry matter) in the leaves of the evaluated Fabaceae species. ${ }^{\mathrm{a}}$ Results are presented as estimated marginal mean \pm standard error.

\begin{tabular}{|c|c|c|c|c|c|c|c|c|c|c|c|c|c|}
\hline & & Puerarin & Daidzin & Genistin & Daidzein & Glycitein & Genistein & Pratensein & Formononetin & Irilone & Prunetin & $\begin{array}{l}\text { Biochanin } \\
\text { A }\end{array}$ & Total \\
\hline \multirow{9}{*}{$\begin{array}{l}\text { Plant } \\
\text { species } \\
\text { (PSp) }\end{array}$} & $\begin{array}{l}\text { Biserrula pelecinus } \\
\text { L. }\end{array}$ & nd & nd & $65 \pm 3$ & $21 \pm 2$ & $\begin{array}{l}2.2 \pm \\
0.4\end{array}$ & $80 \pm 4$ & $5.7 \pm 0.1$ & $62 \pm 3$ & $14 \pm 1$ & nd & $\begin{array}{l}2488 \pm \\
16\end{array}$ & $\begin{array}{l}2739 \pm \\
15\end{array}$ \\
\hline & $\begin{array}{l}\text { Lotus } \\
\text { conimbricensis Brot. }\end{array}$ & nd & nd & $11 \pm 1$ & $\begin{array}{l}3.4 \pm \\
0.3\end{array}$ & $\begin{array}{l}4.1 \pm \\
0.5\end{array}$ & $73 \pm 5$ & $114 \pm 7$ & nd & $20 \pm 1$ & $10 \pm 1$ & $\begin{array}{l}3186 \pm \\
100\end{array}$ & $\begin{array}{l}3422 \pm \\
113\end{array}$ \\
\hline & $\begin{array}{l}\text { Lotus subbiflorus } \\
\text { Lag. }\end{array}$ & nd & $\begin{array}{l}2.1 \pm \\
0.1\end{array}$ & $54 \pm 2$ & $\begin{array}{l}6.8 \pm \\
0.1\end{array}$ & nd & $128 \pm 7$ & $265 \pm 7$ & nd & $9 \pm 1$ & $63 \pm 1$ & $781 \pm 4$ & $\begin{array}{l}1308 \pm \\
4\end{array}$ \\
\hline & $\begin{array}{l}\text { Ornithopus } \\
\text { compressus L. }\end{array}$ & nd & $99 \pm 1$ & $31 \pm 3$ & $\begin{array}{l}8.3 \pm \\
0.1\end{array}$ & $\begin{array}{l}7.3 \pm \\
0.4\end{array}$ & $16 \pm 1$ & $8.8 \pm 0.4$ & $13 \pm 1$ & $16 \pm 1$ & $13 \pm 1$ & $48 \pm 1$ & $260 \pm 1$ \\
\hline & $\begin{array}{l}\text { Ornithopus } \\
\text { pinnatus (Mill.) } \\
\text { Druce }\end{array}$ & nd & $\begin{array}{l}12.9 \pm \\
0.2\end{array}$ & $\begin{array}{l}291 \pm \\
14\end{array}$ & $29 \pm 2$ & $23 \pm 1$ & $23 \pm 2$ & $13 \pm 1$ & nd & $14 \pm 1$ & nd & nd & $405 \pm 2$ \\
\hline & $\begin{array}{l}\text { Ornithopus sativus } \\
\text { Brot. }\end{array}$ & nd & $\begin{array}{l}12.2 \pm \\
0.3\end{array}$ & $12 \pm 1$ & $\begin{array}{l}4.2 \pm \\
0.1\end{array}$ & nd & $40 \pm 3$ & $23 \pm 2$ & $9.6 \pm 0.5$ & $21 \pm 2$ & $22 \pm 1$ & $17 \pm 1$ & $161 \pm 1$ \\
\hline & $\begin{array}{l}\text { Scorpiurus } \\
\text { muricatus L. }\end{array}$ & $\begin{array}{l}9.1 \pm \\
0.1\end{array}$ & $\begin{array}{l}8.8 \pm \\
0.1\end{array}$ & $19 \pm 1$ & $\begin{array}{l}12.1 \pm \\
0.1\end{array}$ & $12 \pm 1$ & $35 \pm 2$ & $6.0 \pm 0.5$ & nd & $\begin{array}{l}0.6 \pm \\
0.1\end{array}$ & nd & $3.2 \pm 0.1$ & $106 \pm 1$ \\
\hline & $\begin{array}{l}\text { Scorpiurus } \\
\text { vermiculata L. }\end{array}$ & nd & $\begin{array}{l}12.0 \pm \\
0.5\end{array}$ & $11 \pm 1$ & $\begin{array}{l}8.1 \pm \\
0.1\end{array}$ & $51 \pm 3$ & nd & $99 \pm 4$ & nd & $34 \pm 3$ & nd & nd & $215 \pm 1$ \\
\hline & $\begin{array}{l}\text { Scorpiurus } \\
\text { vermiculatus L. }\end{array}$ & $\begin{array}{l}2.0 \pm \\
0.1\end{array}$ & $\begin{array}{l}1.0 \pm \\
0.1\end{array}$ & $37 \pm 2$ & $18 \pm 1$ & $33 \pm 1$ & $9 \pm 1$ & $26 \pm 2$ & $88 \pm 4$ & $99 \pm 7$ & $\begin{array}{l}1.4 \pm \\
0.1\end{array}$ & $13 \pm 1$ & $328 \pm 1$ \\
\hline \multicolumn{2}{|c|}{$\begin{array}{l}\text { Mauchly's test of sphericity } \\
\text { ( } p \text {-value) } \\
p \text {-value }{ }^{\mathrm{a}}\end{array}$} & $\begin{array}{l}<0.001 \\
(<0.001) \\
<0.001\end{array}$ & $\begin{array}{l}<0.001 \\
(<0.001) \\
<0.001\end{array}$ & $\begin{array}{l}<0.001 \\
(<0.001) \\
<0.001\end{array}$ & $\begin{array}{l}<0.001 \\
(<0.001) \\
<0.001\end{array}$ & $\begin{array}{l}<0.001 \\
(<0.001) \\
<0.001\end{array}$ & $\begin{array}{l}<0.001 \\
(0.001) \\
<0.001\end{array}$ & $\begin{array}{l}<0.001 \\
(<0.001) \\
<0.001\end{array}$ & $\begin{array}{l}<0.001 \\
(<0.001) \\
<0.001\end{array}$ & $\begin{array}{l}<0.001 \\
(<0.001) \\
<0.001\end{array}$ & $\begin{array}{l}<0.001 \\
(<0.001) \\
<0.001\end{array}$ & $\begin{array}{l}<0.001 \\
(<0.001) \\
<0.001\end{array}$ & $\begin{array}{l}<0.001 \\
(<0.001) \\
<0.001\end{array}$ \\
\hline \multirow{3}{*}{$\begin{array}{l}\text { Phenologic } \\
\text { stage } \\
(\mathrm{PhS})^{\mathrm{b}}\end{array}$} & $\begin{array}{l}\text { Vegetative } \\
\text { elongation }\end{array}$ & $\begin{array}{l}2.7 \pm \\
0.1\end{array}$ & $21 \pm 1$ & $64 \pm 4$ & $13 \pm 1$ & $11 \pm 1$ & $62 \pm 3$ & $45 \pm 3$ & $17.9 \pm 0.5$ & $25 \pm 1$ & $16 \pm 1$ & $753 \pm 3$ & $\begin{array}{l}1029 \pm \\
3\end{array}$ \\
\hline & Late bud & $\begin{array}{l}1.0 \pm \\
0.1\end{array}$ & $18 \pm 2$ & $71 \pm 5$ & $12 \pm 1$ & $14 \pm 1$ & $45 \pm 2$ & $83 \pm 2$ & $27 \pm 2$ & $32 \pm 4$ & $12 \pm 1$ & $782 \pm 33$ & $\begin{array}{l}1098 \pm \\
38\end{array}$ \\
\hline & Late flowering & nd & $11 \pm 1$ & $42 \pm 1$ & $11 \pm 1$ & $19 \pm 4$ & $28 \pm 1$ & $58 \pm 1$ & $13 \pm 1$ & $18 \pm 1$ & $8 \pm 1$ & $644 \pm 5$ & $853 \pm 5$ \\
\hline \multicolumn{2}{|c|}{$\begin{array}{l}\text { Mauchly's test of sphericity } \\
\text { ( } p \text {-value) }\end{array}$} & $\begin{array}{l}0.688 \\
(0.154)\end{array}$ & $\begin{array}{l}0.873 \\
(0.508)\end{array}$ & $\begin{array}{l}0.812 \\
(0.353)\end{array}$ & $\begin{array}{l}0.939 \\
(0.728)\end{array}$ & $\begin{array}{l}0.683 \\
(0.148)\end{array}$ & $\begin{array}{l}0.071 \\
(<0.001)\end{array}$ & $\begin{array}{l}0.039 \\
(0.001)\end{array}$ & $\begin{array}{l}0.698 \\
(0.165)\end{array}$ & $\begin{array}{l}0.250 \\
(0.001)\end{array}$ & $\begin{array}{l}0.386 \\
(<0.001)\end{array}$ & $\begin{array}{l}0.066 \\
(<0.001)\end{array}$ & $\begin{array}{l}0.071 \\
(<0.001)\end{array}$ \\
\hline$p$-value ${ }^{\mathrm{a}}$ & & $<0.001$ & $<0.001$ & $<0.001$ & $<0.001$ & $<0.001$ & $<0.001$ & $<0.001$ & $<0.001$ & $<0.001$ & $<0.001$ & 0.003 & $<0.001$ \\
\hline $\mathrm{PSp} \times \mathrm{PhS}$ & $\begin{array}{l}\text { Mauchly's test of } \\
\text { sphericity } \\
\text { ( } p \text {-value) }\end{array}$ & $\begin{array}{l}<0.001 \\
(<0.001)\end{array}$ & $\begin{array}{l}<0.001 \\
(<0.001)\end{array}$ & $\begin{array}{l}<0.001 \\
(<0.001)\end{array}$ & $\begin{array}{l}<0.001 \\
(<0.001)\end{array}$ & $\begin{array}{l}<0.001 \\
(<0.001)\end{array}$ & $\begin{array}{l}0.001 \\
(<0.001)\end{array}$ & $\begin{array}{l}<0.001 \\
(<0.001)\end{array}$ & $\begin{array}{l}<0.001 \\
(<0.001)\end{array}$ & $\begin{array}{l}<0.001 \\
(<0.001)\end{array}$ & $\begin{array}{l}<0.001 \\
(<0.001)\end{array}$ & $\begin{array}{l}<0.001 \\
(<0.001)\end{array}$ & $\begin{array}{l}<0.001 \\
(<0.001)\end{array}$ \\
\hline$p$-value ${ }^{a}$ & & $<0.001$ & $<0.001$ & $<0.001$ & $<0.001$ & $<0.001$ & $<0.001$ & $<0.001$ & $<0.001$ & $<0.001$ & $<0.001$ & 0.002 & 0.002 \\
\hline
\end{tabular}

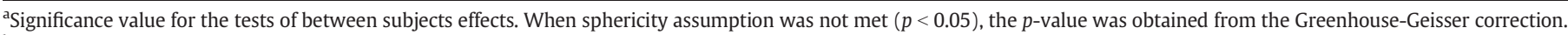

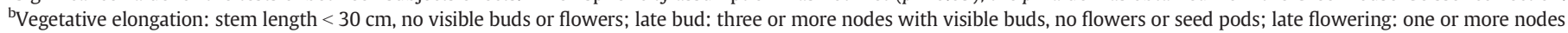
with $50 \%$ open flowers, no seed pods.

The pairwise assessment of both factors (PSp and PhS) simultaneously, allowed to verify the higher effect of the plants phylogeny, which induced the highest changes, despite the taxonomical proximity of the assayed species. Nevertheless, these plants showed different physiological behavior (e.g., in the periods of sowing, elongation, transplantation or flowering), which might also contribute to explain some of the detected differences in response to the environmental conditions experienced throughout their vegetative development (Bednarek et al., 2003; Sakthivelu et al., 2008; Von Baer et al., 2006). In fact, the modulating influence of ontogenic factors was previously reported in T. pratense, which revealed higher isoflavone contents at the early bud and late flowering stages, but also a clear decline in formononetin and biochanin A levels just before flowering (Sivesind \& Seguin, 2005; Tsao et al., 2006) and also in L. albus, which yielded higher isoflavone contents (especially in genistein-7-0-glucoside) in spring-sown plants (D'Agostina et al., 2008). A similar behavior was also verified in G. $\max$ (Guo, Kong, Wang, \& Wang, 2011; Simonne et al., 2000; Zhang et al., 2006) and Medicago sativa (Seguin, Zheng, \& Souleimanov, 2004).

\subsection{Linear discriminant analysis (LDA)}

In order to obtain a global understanding regarding the influence of genotypic and ontogenic effects over isoflavone profiles, the results were evaluated simultaneously through LDA, verifying which variables (isoflavones) contributed mostly to differentiate plant species or phenologic stages. The data matrix was composed of 324 lines ( 2 accessions $\times 9$ species $\times 3$ phenologic stages $\times 3$ plantlets/species $\times 2$ extractions) $\times 11$ columns (quantified isoflavones). The significant independent variables were selected using the stepwise procedure of the LDA, according to the Wilks' $\lambda$ test, which maintains only those with a statistically significant $(p<0.05)$ classification ability.

From the results presented in Table 1, it might be anticipated that the isoflavone profiles are strongly determined by the plant species. Accordingly, the LDA was applied considering the four genera as the discriminating factor. The three defined functions, plotted in Fig. 2, included $100.0 \%$ of the observed variance (first: $64.1 \%$; second: $20.7 \%$; third: $15.2 \%)$. In this discriminant model, all isoflavones were selected as significant independent variables. Considering the correlation between discriminating variables and standardized canonical discriminant functions, function 1 was more powerfully correlated with biochanin A and genistein. According to this function, one cluster composed by Biserrula and Lotus genera markers was individualized due to their higher quantities in bioachanin A and genistein, when compared to Ornithopus and Scorpiurus, which formed a second cluster. Function 2 , on the other hand, was mostly correlated to formononetin and prunetin, highlighting their similar values in Biserrula and Scorpiurus, in one way, while separating Lotus and Ornithopus, as a second group. Finally, function 3 was highly correlated to pratensein, thereby contributing to form two main groups, one constituted by Biserrula and Ornithopus (with low scores regarding pratensein) and a second composed by Lotus and Scorpiurus (which generally presented high levels of pratensein). Despite the pointed out similarities among different genera, the classification performance was $100 \%$ accurate, either for the originally grouped cases, as well as for the cross-validated cases. This result is clearly elucidated in Fig. 2, as shown by the observable separation of clusters corresponding to Biserrula (gray dashed ellipse), Lotus (gray 

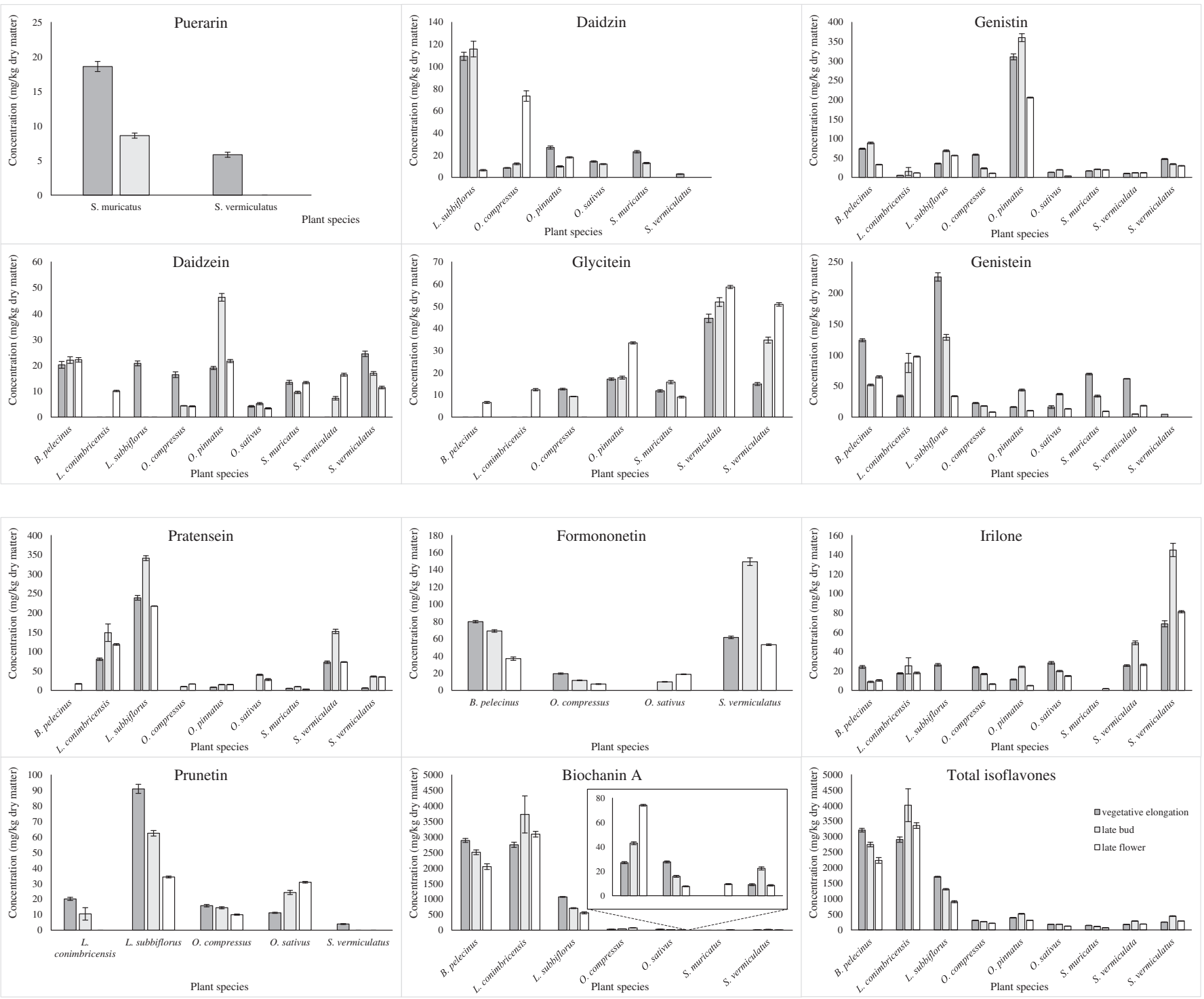

Chemical structure and 3 -D representation of biochanin A.<smiles>COc1ccc(-c2coc3cc(O)cc(O)c3c2=O)cc1</smiles>

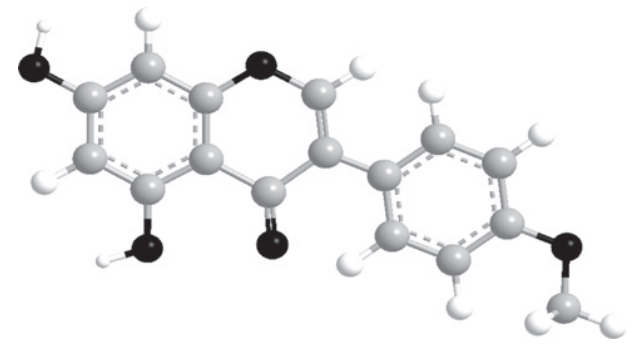

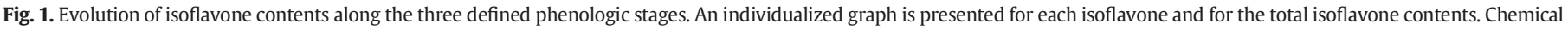
structure and 3-D representation of biochanin A.

shadowed ellipse), Ornithopus (black dashed ellipse) and Scorpiurus (black shadowed ellipse).

Regarding the differences resulting from harvesting the plants in different phenologic stages, the LDA clearly demonstrates that the influence of this factor on the isoflavone profiles is less pronounced. Even though, puerarin and genistein, more highly correlated to function 1 , and pratensein and irilone, mainly correlated with function 2 , were the variables with the highest differences among the assayed phenologic stages. In terms of classification performance, the corresponding contingency matrix (Table 2) gave low values of sensitivity and overall specificity, either for original group cases (57.4\% and $56.4 \%$, respectively), as well as for the leave-one-out cross-validation procedure (sensitivity: $55.6 \%$; specificity: $54.5 \%$ ), which indicates a high number of misclassified cases. Despite the detected differences were not strong enough to separate the markers corresponding to each group (Fig. 3), some overall tendencies could be obtained. Independently of the PSp, the highest contents in puerarin, genistiein, prunetin and daidzein were obtained in the VE stage; conversely, the 


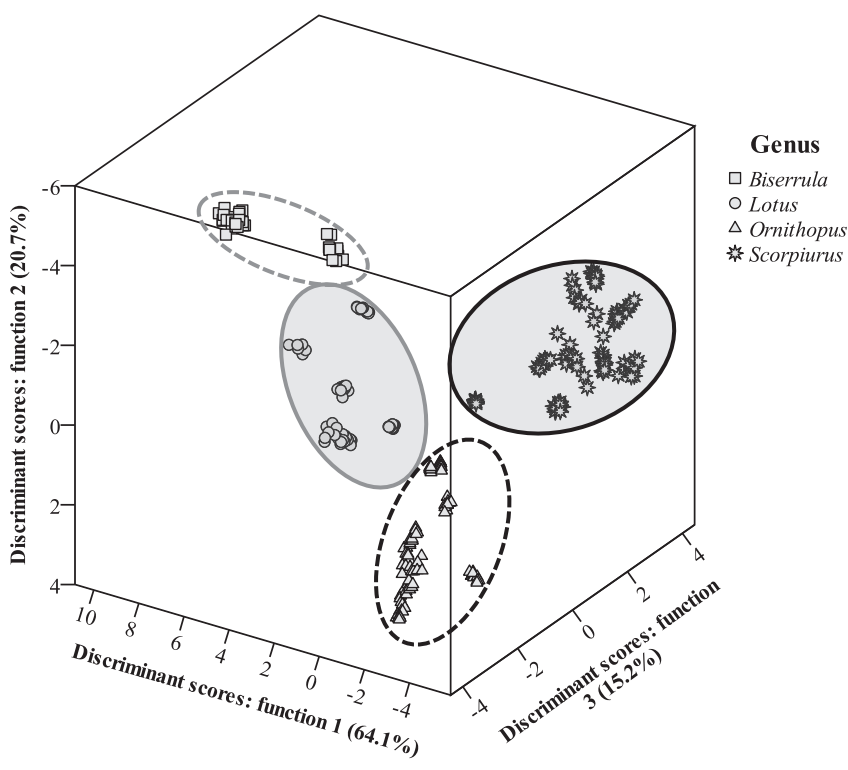

Fig. 2. Canonical analysis based on isoflavone profiles using the studied genera as discriminant factor. The ellipses highlight the clear separation of the four naturally occurring groups.

contents of pratensein, irilone, formononetin, genistin and bioachanin A were measured in the LB stage; on the other hand, glycitein was the only isoflavone whose maximum values were obtained in the LF stage.

\section{Conclusion}

In spite of belonging to the same family, the studied species revealed significant differences on their isoflavone profiles. The ontogenic factors had a less pronounced effect, but it was possible to identify the vegetative stage where each of the detected isoflavones reached the maximum contents throughout the plant development, which represents a very important result to obtain a more accurate prediction about the achievable isoflavone yields. The plant species from the Biserrula and Lotus genera stood out as the most promising new natural sources of isoflavones, especially considering their high levels of biochanin A. Independently of plant species or isoflavone type, knowing the exact amounts produced in each case is essential to design novel food products, taking into account that the effects of isoflavones on the human body are highly dependent on the uptake concentration.

Table 2

Contingency matrix obtained using LDA based on antioxidant activity and antioxidant contents of sweet orange varieties (OV).

\begin{tabular}{|c|c|c|c|c|c|}
\hline \multirow[b]{2}{*}{ Phenologic stage } & \multicolumn{3}{|c|}{ Predicted group membership } & \multirow[b]{2}{*}{ total } & \multirow[b]{2}{*}{$\begin{array}{l}\text { Sensitivity } \\
(\%)\end{array}$} \\
\hline & $\begin{array}{l}\text { Vegetative } \\
\text { elongation }\end{array}$ & $\begin{array}{l}\text { Late } \\
\text { bud }\end{array}$ & $\begin{array}{l}\text { Late } \\
\text { flowering }\end{array}$ & & \\
\hline \multicolumn{6}{|c|}{ Original group cases } \\
\hline $\begin{array}{l}\text { Vegetative } \\
\text { elongation }\end{array}$ & 81 & 15 & 12 & 108 & 75.0 \\
\hline Late bud & 30 & 42 & 36 & 108 & 38.9 \\
\hline Late flowering & 12 & 33 & 63 & 108 & 58.3 \\
\hline total & 123 & 90 & 111 & 324 & 57.4 \\
\hline Specificity (\%) & 65.8 & 46.7 & 56.8 & 56.4 & \\
\hline \multicolumn{6}{|c|}{ Cross-validated group cases } \\
\hline $\begin{array}{l}\text { Vegetative } \\
\text { elongation }\end{array}$ & 77 & 19 & 12 & 108 & 71.3 \\
\hline Late bud & 30 & 42 & 36 & 108 & 39.8 \\
\hline Late flowering & 12 & 36 & 60 & 108 & 55.6 \\
\hline total & 119 & 97 & 108 & 324 & 55.6 \\
\hline Specificity (\%) & 64.7 & 43.3 & 55.6 & 54.5 & \\
\hline
\end{tabular}

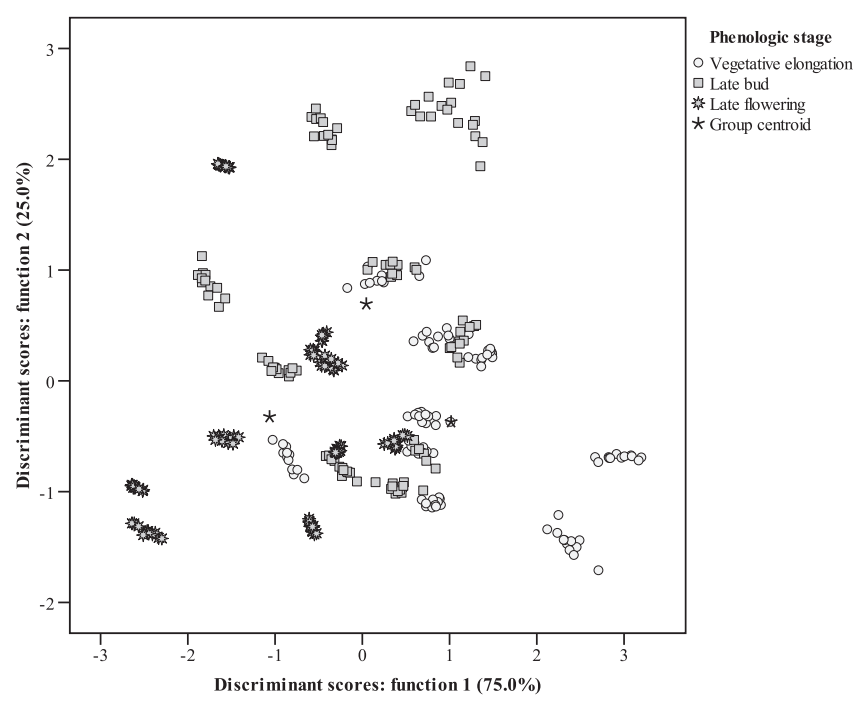

Fig. 3. Canonical analysis based on isoflavone profiles using the studied genera (A) and the phenologic stage (B) as discriminant factors.

\section{Acknowledgments}

João C.M. Barreira and T. Visnevschi-Necrasov are grateful to "FCT Fundação para a Ciência e a Tecnologia” for their grants (SFRH/BPD/ $72802 / 2010$ and SFRH/BD/31734/2006, respectively) financed by POPH-QREN and subsidized by FSE and MCTES. This work received financial support from the European Union (FEDER funds through COMPETE) and National Funds (FCT) through project Pest-C/EQB/LA0006/ 2013. The work also received financial support from the European Union (FEDER funds) under the framework of QREN through Project NORTE-07-0124 FEDER-000069.

\section{References}

Azarova, A. M., Lin, R. K., Tsai, Y. C., Liu, L. F., Lin, C. P., \& Lyu, Y. L. (2010). Genistein induces topoisomerase II beta- and proteasome-mediated DNA sequence rearrangements: Implications in infant leukemia. Biochemical and Biophysical Research Communications, 399, 66-71.

Barreira, J. C. M., Visnevschi-Necrasov, T., Nunes, E., Cunha, S. C., Pereira, G., \& Oliveira, M. B.P. P. (2015). Medicago spp. as potential sources of bioactive isoflavones: Characterization according to phylogenetic and phenologic factors. Phytochemistry, 116, 230-238.

Bednarek, P., Franski, R., Kerhoas, L., Einhorn, J., Wojtaszek, P., \& Stobiecki, M. (2001). Profiling changes in metabolism of isoflavonoids and their conjugates in Lupinus albus treated with biotic elicitor. Phytochemistry, 56, 77-85

Bednarek, P., Kerhoas, L., Einhorn, J., Franski, R., Wojtaszek, P., Rybus-Zajac, M., \& Stobiecki, M. (2003). Profiling of flavonoid conjugates in Lupinus albus and Lupinus angustifolius responding to biotic and abiotic stimuli. Journal of Chemical Ecology, 29, 1127-1142.

Boerma, H. R., John, J. S., \& Molen, J. Y. (2001, July 30-31). U.S. legume crops genomics workshop. (Hunt Valley, Maryland. White Paper).

Bucar, F. (2013). Phytoestrogens in plants: With special reference to isoflavones. In V. R. Preedy (Ed.), Isoflavones: Chemistry, analysis, function and effects (pp. 14-27). Royal Society of Chemistry Publishing.

Cano, A., García-Pérez, M. A., \& Tarín, J. J. (2010). Isoflavones and cardiovascular disease. Maturitas, 67, 219-226.

D'Agostina, A., Boschin, G., Resta, D., Anniccniarico, P., \& Arnoldi, A. (2008). Changes of isoflavones during the growth cycle of Lupinus albus. Journal of Agricultural and Food Chemistry, 56, 4450-4456.

Diaz, P., Borsani, O., \& Monza, J. (2005). Lotus-related species and their agronomic importance. In A. J. Márquez (Ed.), Lotus japonicus handbook (pp. 25-37). Springer.

Food Safety Commission Novel Foods Expert Committee (2006). Fundamental concepts in the safety assessment of foods containing soy isoflavones for the purpose of specified health use. , 1-54 (http://www.fsc.go.jp/english/evaluationreports/newfoods sphealth/soy_isoflavones.pdf. Accessed 16.04.26).

Gepts, P., Beavis, W. D., Brummer, E. C., Shoemaker, R. C., Stalker, H. T., Weeden, N. F., \& Young, N. D. (2005). Legumes as a model plant family. Genomics for food and feed report of the cross-legume advances through genomics conference. Plant Physiology, 137, 1228-1235.

Guo, Z. Y., Kong, C. -H., Wang, J. -G., \& Wang, Y. -F. (2011). Rhizosphere isoflavones (daidzein and genistein) levels and their relation to the microbial community structure of 
mono-cropped soybean soil in field and controlled conditions. Soil Biology and Biochemistry, 43, 2257-2264.

Hackney, B., Dear, B., \& Crocker, G. (2007). Biserrula. Primfact: Profitable E' sustainable primary industries (pp. 632).

Jacobs, A., Wegewitz, U., Sommerfeld, C., Grossklaus, R., \& Lampen, A. (2009). Efficacy of isoflavones in relieving vasomotor menopausal symptoms - a systematic review. Molecular Nutrition and Food Research, 53, 1084-1097.

Jalaludeen, A. M., Lee, W. Y., Kim, J. H., Jeong, H. Y., Ki, K. S., Kwon, E. G., \& Song, H. (2015) Therapeutic efficacy of biochanin A against arsenic-induced renal and cardiac damage in rats. Environmental Toxicology and Pharmacology, 39, 1221-1231.

Krenn, L., Unterrieder, I., \& Ruprechter, R. (2002). Quantification of isoflavones in red clover by high-performance liquid chromatography. Journal of Chromatography B, 777, $123-128$.

Kumar, V., Rani, A., Dixit, A. K., Bhatnagar, D., \& Chauhan, G. S. (2009). Relative changes in tocopherols, isoflavones, total phenolic content, and antioxidative activity in soybean seeds at different reproductive stages. Journal of Agricultural and Food Chemistry, 57, $2705-2710$.

Lewis, G., Schrire, B., Mackinder, B., \& Lock, M. (2005). Legumes of the world. Kew: Royal Botanic Gardens (577 pp.).

Mortensen, A., Kulling, S. E., Schwartz, H., Rowland, I., Ruefer, C. E., Rimbach, G., ... Sontag G. (2009). Review: Analytical and compositional aspects of isoflavones in food and their biological effects. Molecular Nutrition and Food Research, 53, 266-309.

Mourouti, N., \& Panagiotakos, D. B. (2013). Soy food consumption and breast cancer. Maturitas, 76, 118-122.

Nandasena, K. G., O'Hara, G. W., Tiwari, R. P., Yates, R. J., Kishinevsky, B. D., \& Howieson, J. G. (2004). Symbiotic relationships and root nodule ultrastructure of the pasture legume Biserrula pelecinus L. - A new legume in agriculture. Soil Biology E Biochemistry, 36, 1309-1317.

Nemitz, M. C., Argenta, D. F., Koester, L. S., Bassani, V. L., von Poser, G. L., \& Teixeira, H. F. (2016). The international scenario of patents concerning isoflavones. Trends in Food Science E' Technology, 49, 85-95.

Palacios-Morillo, A., Alcázar, Á., Pablos, F., \& Jurado, J. M. (2013). Differentiation of tea varieties using UV-Vis spectra and pattern recognition techniques. Spectrochimica Acto Part A: Molecular and Biomolecular Spectroscopy, 103, 79-83.

Park, C. Y., \& Weaver, C. M. (2012). Vitamin D interactions with soy isoflavones on bone after menopause: A review. Nutrients, 4, 1610-1621.

Piegholdt, S., Pallauf, K., Esatbeyoglu, T., Speck, N., Reiss, K., Ruddigkeit, L., ... Rimbach, G. (2014). Biochanin A and prunetin improve epithelial barrier function in intestinal CaCo-2 cells via downregulation of ERK, NF-kB, and tyrosine phosphorylation. Free Radical Biology and Medicine, 70, 255-264.

Russo, M., Russo, G. L., Daglia, M., Kasi, P. D., Ravi, S., Nabavi, S. F., \& Nabavi, S. M. (2016). Understanding genistein in cancer: The "good" and the "bad" effects: A review. Food Chemistry, 196, 589-600.

Sacks, F. M., Lichtenstein, A., Van Horn, L., Harris, W., Kris-Etherton, P., \& Winston, M. (2006). Soy protein, isoflavones, and cardiovascular health: An American Heart Association science advisory for professionals from the nutrition committee. Circulation, $113,1034-1044$

Sakthivelu, G., Devi, M. K. A., Giridar, P., Rajasekaran, T., Ravishankar, G. A., Nikolova, M. T., ... Kosturkova, G. P. (2008). Isoflavone composition, phenol content, and antioxidant activity of soybean seeds from India and Bulgaria. Journal of Agricultural and Food Chemistry, 56, 2090-2095.
Seguin, P., Zheng, W., \& Souleimanov, A. (2004). Alfalfa phytoestrogen content: Impact of plant maturity and herbage components. Journal of Agronomy and Crop Science, 190, 211-217.

Setchell, K. D., \& Cassidy, A. (1999). Dietary isoflavones: Biological effects and relevance to human health. Journal of Nutrition, 129, 758S-767S.

Simonne, A. H., Smith, M., Weaver, D. B., Vail, T., Barnes, S., \& Wei, C. I. (2000). Retention and changes of soy isoflavones and carotenoids in immature soybean seeds (Edamame) during processing. Journal of Agricultural and Food Chemistry, 48, 6061-6069.

Sithisarn, P., Michaelis, M., Schubert-Zsilavecz, M., \& Cinatl, J., Jr. (2013). Differential antiviral and anti-inflammatory mechanisms of the flavonoids biochanin A and baicalein in H5N1 influenza A virus-infected cells. Antiviral Research, 97, 41-48.

Sivesind, E., \& Seguin, P. (2005). Effects of the environment, cultivar, maturity, and preservation method on red clover isoflavone concentration. Journal of Agricultural and Food Chemistry, 53, 6397-6402.

Spínola, V., Llorent-Martínez, E. J., Gouveia-Figueira, S., \& Castilho, P. C. (2016). Ulex europaeus: From noxious weed to source of valuable isoflavones and flavanones. Industrial Crops and Products, 90, 9-27.

Tolleson, W. H., Doerge, D. R., Churchwell, M. I., Marques, M. M., \& Roberts, D. W. (2002). Metabolism of biochanin A and formononetin by human liver microsomes in vitro. Journal of Agricultural and Food Chemistry, 50, 4783-4790.

Tsao, R., Papadopoulos, Y., Yang, R., Young, J. C., \& McRae, K. (2006). Isoflavone profiles of red clovers and their distribution in different parts harvested at different growing stages. Journal of Agricultural and Food Chemistry, 54, 5797-5805.

U.S. Department of Agriculture, Agricultural Research Service (2008i). USDA database for the isoflavone content of selected foods, release 2.0. http://www.ars.usda.gov/ SP2UserFiles/Place/12354500/Data/isoflav/Isoflav_R2.pdf (Accessed 16.04.26)

Visnevschi-Necrasov, T., Barreira, J. C. M., Cunha, S. C., Pereira, G., Nunes, E., \& Oliveira, M. B. P. P. (2014). Advances in isoflavone profiles characterization using matrix solidphase dispersion coupled to HPLC-DAD in Medicago species. Phytochemical Analysis, 26, 40-46.

Visnevschi-Necrasov, T., Barreira, J. C. M., Cunha, S. C., Pereira, G., Nunes, E., \& Oliveira, M. B. P. P. (2015). Phylogenetic insights on the isoflavone profile variations in Fabaceae spp.: Assessment through PCA and LDA. Food Research International, 76, 51-57.

Von Baer, D., Saelzer, R., Vega, M., Ibieta, P., Molina, L., Von Baer, E., ... Hashagen, U. (2006). Isoflavones in Lupinus albus and Lupinus angustifolius: Quantitative determination by capillary zone electrophoresis, evolution of their concentration during plant development and effect on anthracnose causing fungus Colletotrichum lupini. Journal of the Chilean Chemical Society, 51, 1025-1029.

Wang, J., He, C., Wu, W. -Y., Chen, F., Wu, Y. -Y., Li, W. -Z., ... Yin, Y. -Y. (2015). Biochanin A protects dopaminergic neurons against lipopolysaccharide-induced damage and oxidative stress in a rat model of Parkinson's disease. Pharmacology Biochemistry and Behavior, 138, 96-103.

Ye, R., Bodero, A., Zhou, B. B., Khanna, K. K., Lavin, M. F., \& Lees-Miller, S. P. (2001). The plant isoflavenoid genistein activates p53 and Chk2 in an ATM-dependent manner. Journal of Biological Chemistry, 276, 4828-4833.

Zhang, B., Hettiarachchy, N., Chen, P., Horax, R., Cornelious, B., \& Zhu, D. (2006). Influence of the application of three different elicitors on soybean plants on the concentrations of several isoflavones in soybean seeds. Journal of Agricultural and Food Chemistry, 54, 5548-5554. 